Additional services for Cardiology in the Young:

Email alerts: $\underline{\text { Click here }}$

Subscriptions: $\underline{\text { Click here }}$

Commercial reprints: $\underline{\text { Click here }}$

Terms of use : $\underline{\text { Click here }}$

\title{
Twisted atrioventricular connections in double inlet right ventricle: evaluation by magnetic resonance imaging
}

Tae Hoon Kim, Shi-Joon Yoo, Siew Yen Ho and Robert H. Anderson

Cardiology in the Young / Volume 10 / Issue 06 / November 2000, pp 567 - 573

DOI: 10.1017/S1047951100008830, Published online: 19 August 2008

Link to this article: http://journals.cambridge.org/abstract_S1047951100008830

How to cite this article:

Tae Hoon Kim, Shi-Joon Yoo, Siew Yen Ho and Robert H. Anderson (2000). Twisted atrioventricular connections in double inlet right ventricle: evaluation by magnetic resonance imaging. Cardiology in the Young,10, pp 567-573 doi:10.1017/ S1047951100008830

Request Permissions : $\underline{\text { Click here }}$ 


\title{
Twisted atrioventricular connections in double inlet right ventricle: evaluation by magnetic resonance imaging
}

\author{
Tae Hoon Kim, ${ }^{1}$ Shi-Joon Yoo, ${ }^{1,2}$ Siew Yen Ho, ${ }^{3}$ Robert H. Anderson ${ }^{4}$ \\ 'Department of Radiology, Sejong Heart Institute, Pucheon, Korea; ${ }^{2}$ Department of Diagnostic Imaging, Hospital for Sick \\ Children, Unwersity of Toronto, Toronto, Canada; ${ }^{3}$ Department of Paediatrics, National Heart and Lung Institute, Imperial \\ College School of Medicine, London, United Kingdom; ${ }^{4}$ Cardiac Unit, Instutute of Child Health, University College London, \\ United Kingdom
}

\begin{abstract}
Twisted atrioventricular connections occur almost exclusively in the hearts with biventricular atrioventricular connections. Only one example of double inlet left ventricle has been illustrated in which the axes of the two atrioventricular valves crossed each other. We describe herein three patients, and one autopsied specimen, with double inlet right ventricle in which magnetic resonance imaging clearly demonstrated twisted atrioventricular connections.
\end{abstract}

Keywords: twisted atrioventricular connections, double inlet right ventricle, criss-cross heart, magnetıc resonance

$\mathrm{T}$ HE BLOOD STREAMS FROM THE ATRIUMS TO the ventricles through the atrioventricular valves are parallel to each other in almost all hearts with two atriums and two ventricles. Sometimes this is not the case. In these circumstances, the term "twisted atrioventricular connections" describes well this spectrum of conditions in which the atriums are connected to the underlying ventricles in a spiral fashion as if the heart were twisted along its long axis. ${ }^{1-5}$ When there are twisted atrioventricular connections, the ventricles tend to be related in superoinferior fashion. ${ }^{6-10}$ With a greater degree of twisting, the two blood-streams from the atriums to the ventricles appear to criss-cross. ${ }^{6,8,10}$

Twisted atrioventricular connections occur almost exclusively in hearts in which the atrioventricular connections themselves are biventricular. In a review of the overall spectrum, however, one example of double inlet left ventricle was illustrated in which the axes of the two atrioventricular valves crossed each other within the dominant left ventricle. ${ }^{10}$ This possibility, nonetheless, has not yet

Correspondence to Shi-Joon Yoo, MD, Department of Diagnostic Imaging, Hospital for Sick Children, University of Toronto, 555 Unversity Avenue, Toronto, Ontarıo, MSG 1X8, Canada Tel (416) 813-6037 6029, Fax (416) 813-7591; E-mal. shi-joon.yoo@sıckkıds.on.ca

Accepted for publication 11 April 2000 been validated, either in living individuals or at autopsy. We describe herein three patients, and one specimen, with double inlet right ventricle, in which magnetic resonance imaging clearly demonstrated the twisted nature of the atrioventricular connections.

\section{Materials and methods}

Three patients with known double inlet right ventricle underwent magnetic resonance imaging for accurate evaluation of the cardiovascular anatomy. Diagnosis prior to resonance imaging had been made by echocardiography and angiography in all. The data are summarized in the Table. All patients were sedated by oral administration of chloral hydrate (60-80 mg/kg of body weight). An electrocardiographically gated spin-echo technique was used, with the repetition time determined by heart rate and a short echo time. We used a body coil and an 18-25 $\mathrm{cm}$ field of view. Transaxial, coronal, sagittal, right anterior oblique, and left anterior oblique images were obtained at a thickness of $5 \mathrm{~mm}$, and with gaps of $0-20 \%$ of the thickness between the sections. All images were obtained with a $256 \times 128$ matrix, and two signals were averaged. The images were interpreted using sequential segmental analysis. The images obtained using magnetic resonance were 
compared retrospectively with the echocardiograms and cineangiocardiograms. We also evaluated a cardiac specimen having similar basic pathology. So as to facilitate clinico-pathologic correlation, we performed resonance imaging of the specimen by using $\mathrm{T} 1$-weighted spin-echo technique.

\section{Results}

All three patients showed normal arrangement of the abdominal and thoracic organs and atriums
(Table). The heart was positioned in the middle of the chest in one patient, and was right-sided in two. All three patients had double inlet to a dominant right ventricle. Each patient had different ventriculoarterial connections: double outlet right ventricle, single outlet from the dominant right ventricle with pulmonary atresia, and discordant connections, respectively. The spatial relationship of the cardiac chambers was unusual for the given segmental connections (Figs $1-3)$. The right atrium was located to the right of,

Table. Summary of Patient Data

\begin{tabular}{|c|c|c|c|}
\hline Parameter & Case 1 & Case 2 & Case 3 \\
\hline Age / sex & 5 year $/$ male & 4 month / male & 4 month / female \\
\hline Atrial arrangement & Usual & Usual & Usual \\
\hline Heart position & Midline & Right & Right \\
\hline Atrioventricular connections & Double inlet right ventricle & Double inlet right ventricle & Double inlet right ventricle \\
\hline Ventriculoarterial connections & $\begin{array}{l}\text { Double outlet from right } \\
\text { ventricle }\end{array}$ & $\begin{array}{l}\text { Single outlet from right } \\
\text { ventricle }\end{array}$ & Discordant \\
\hline $\begin{array}{l}\text { Position of aorta relative to } \\
\text { pulmonary artery }\end{array}$ & $\begin{array}{l}\text { Anterior and slightly to the } \\
\text { left }\end{array}$ & Directly anterior & Anterior and slightly to the left \\
\hline Direction of twisting & Clockwise & Clockwise & Clockwise \\
\hline Associated malformations & Subpulmonary stenosis & $\begin{array}{l}\text { Pulmonary atresia, patent } \\
\text { arterial duct }\end{array}$ & $\begin{array}{l}\text { Subpulmonary stenosis, left } \\
\text { juxtaposition of the atrial } \\
\text { appendages, atrial septal defect } \\
\text { within oval fossa }\end{array}$ \\
\hline Treatment & Fontan operation & Lost to follow-up & Fontan operation \\
\hline
\end{tabular}

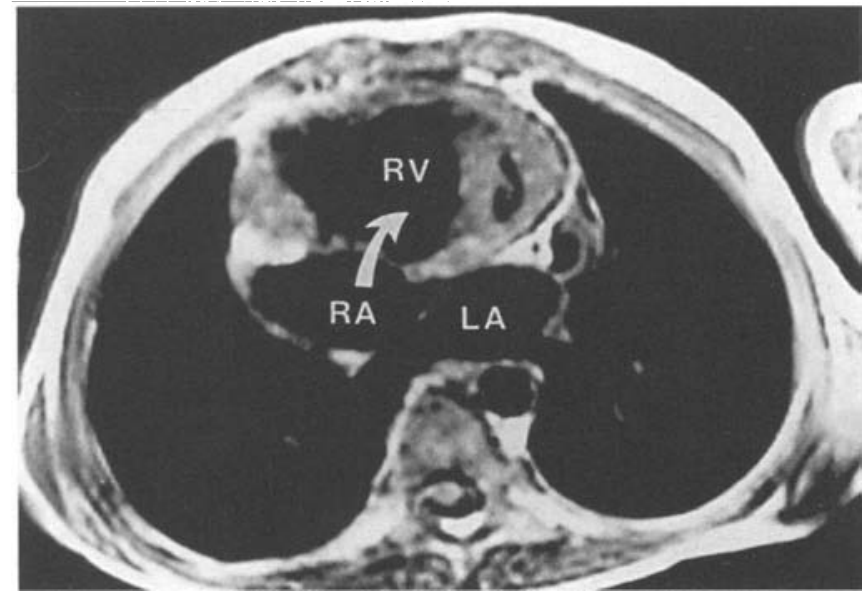

(a)

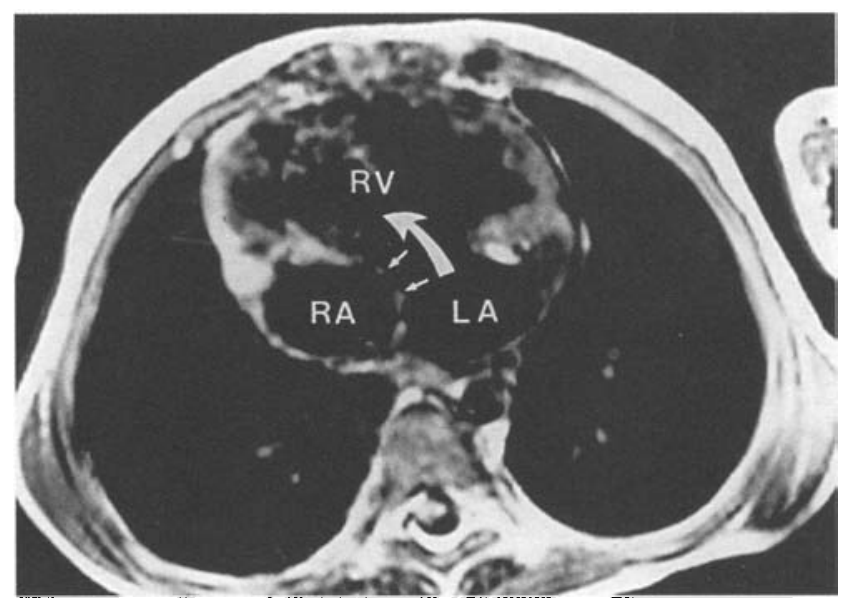

(b)

Figure 1.

Patient \# 1. Double inlet and double outlet right ventricle. Transverse magnetic resonance tmages (TR/TE $=594 \mathrm{msec} / 14 \mathrm{msce})$ in craniocaudal sequence show that the atrioventricular valve of the right atrum $(R A)$ is located superior to that of the left atrum $(L A)$. Both valves are connected to the right ventricle $(R V)$. The opening axis of the atrioventricular valve of the right atrium (arrow in $A$ ) points the left anterior chest wall, while that of the valve of the left atrium (arrow in B) points the right anterior chest wall. Nottce the curved atrial septum (small arrows in $B$ ). 


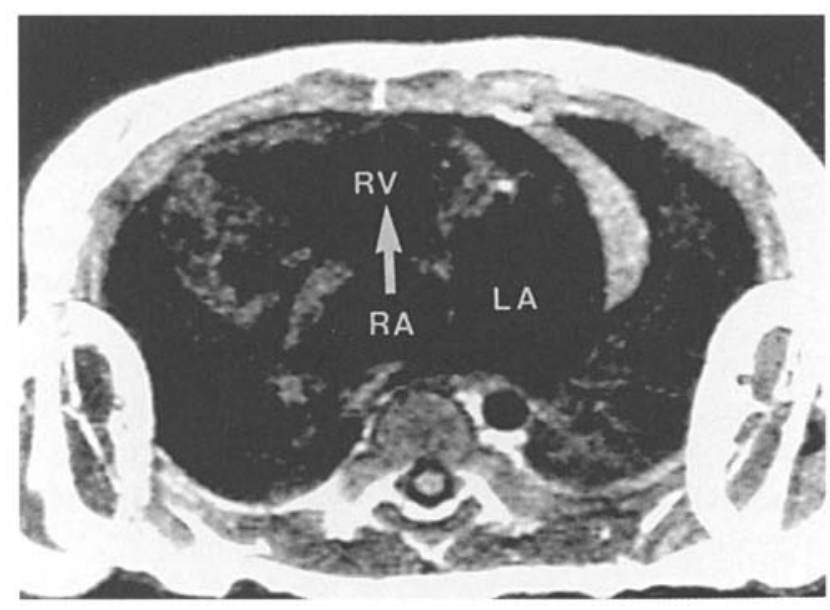

(a)

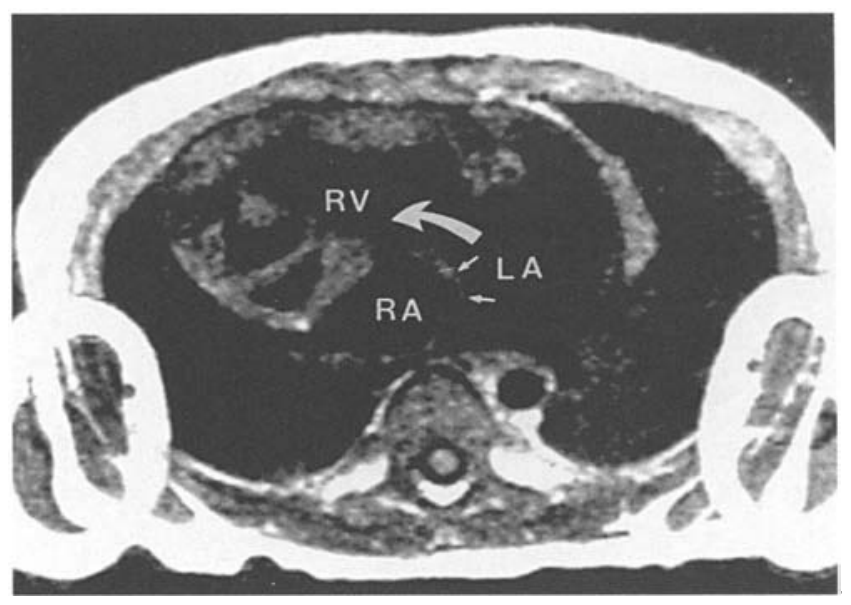

(b)

Figure 2.

Patient \#2. Double inlet right ventricle, the aorta from the right ventricle and pulmonary atresia. Transverse magnetuc resonance images (TR/TE $=400 \mathrm{msec} / 25 \mathrm{msce}$ ) in craniocaudal sequence show superoinferior relationship of the two atrioventricular valves that are connected to the right ventricle $(R V)$ as in Patient 1. The opening axis of the atrioventricular valve of the right atrium (RA) (arrow in $A$ ) points the anterior chest wall, while that of the valve of the left atrum $(L A)$ (arrow in $B$ ) points the right anterior chest wall. The atrial septum shows a curved configuration (small arrows $i n B$ ).

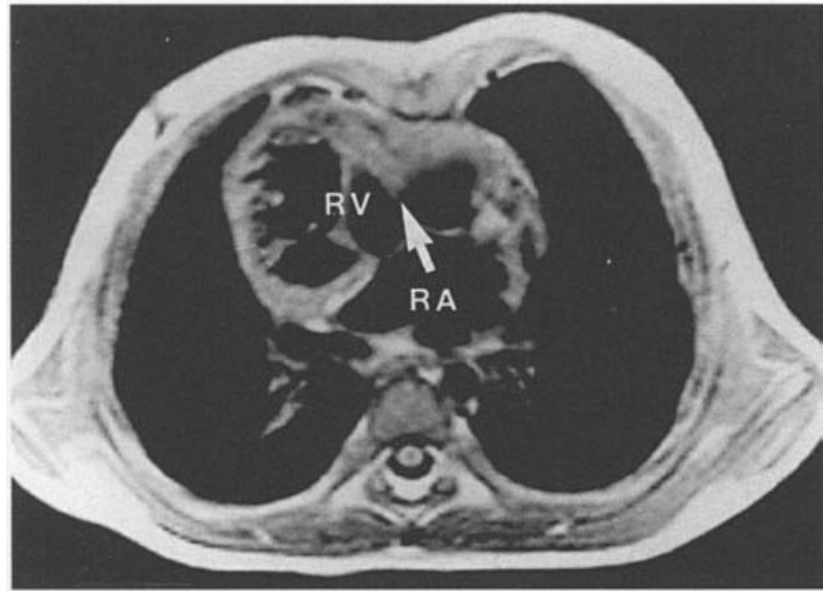

(a)

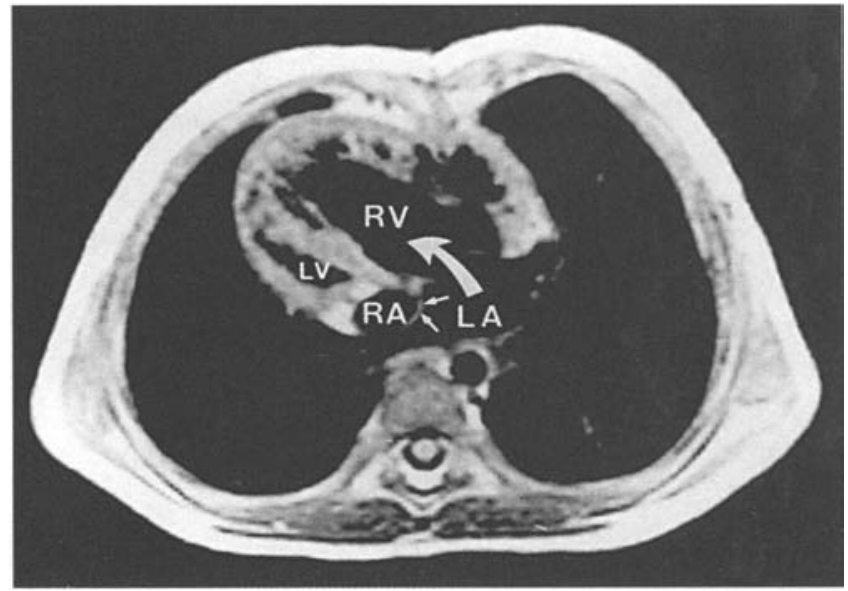

(b)

Figure 3.

Pattent \#3. Double inlet right ventricle with discordant ventriculo-arterial connections. Transverse magnetic resonance images (TR/TE $=$ $644 \mathrm{msec} / 20 \mathrm{msec}$ ) in craniocaudal sequence show superoinferior relationship of the two atrioventricular valves that are connected to the right ventricle $(R V)$. The axes of opening of the two valves are not parallel to each other, and the atrial septum is curved (small arrows in $B$ ). Rudimentary left ventricle $(L V)$ is seen to the right of and inferior to the right ventricle. $L A=$ right atrium, $R A=$ right atrum.

and superior to, the left atrium in all. The rudimentary left ventricle was seen to the right of, and posteroinferior to, the dominant right ventricle in all (Fig. 3b). The ascending aorta was located directly anterior, or left and anterior, relative to the pulmonary trunk. The atrioventricular valve guarding the right atrioventricular junction was superior to that guarding the left, with malalignment of their axes of opening. The axis of the atrioventricular valve of the right atrium was directed more or less anteriorly, while that exiting from the left atrium extended more rightward. It was never possible to image the atrioventricular valves in a single transverse plane in any patient. The atrial septum was abnormal, showing a curved configuration in all, with the convexity toward the left atrium as seen in the transverse images. There was subpulmonary stenosis in two, and pulmonary 
atresia in one. In the case with pulmonary atresia, the confluent pulmonary arteries were supplied by a patent arterial duct. There was left juxtaposition of the atrial appendages in one patient.

The specimen showed normally arranged atriums. The ventricular apex pointed to the right side. The systemic and pulmonary veins were connected to the appropriate atriums. The right atrium was located slightly superior to the left atrium. The atrioventricular valve of the right atrium was divided into two distinct orifices, each of which was supported by its own tension apparatus. The atrioventricular valve of the left atrium was normally formed. The ventricular mass had a dominant right ventricle and a rudimentary and incomplete left ventricle, with the left ventricle to the right of, and posteroinferior to, the right ventricle. The inferior and rightward of the two atrioventricular valvar orifices exiting from the right atrium was connected to the left ventricle. The superior and left orifice of the same valve, and the entire atrioventricular valve of the left atrium, were connected to the dominant right ventricle. Thus, there was double inlet right ventricle, but with straddling and overriding of the right atrioventricular valve, which had dual orifices. The basal parts of the opposing leaflets of the two atrioventricular valves were fused, and there was an oval fenestration in the fused part of the leaflets. Because of this unique location, the fenestration functioned as an interatrial communication. Both the aorta and pulmonary trunk arose from the right ventricle, with the ascending aorta located directly anterior to the pulmonary trunk. Magnetic resonance imaging of the specimen clearly depicted the unusual spatial relationship between the cardiac chambers, revealing correlation with the pathologic findings (Fig. 4).

\section{Discussion}

The term "twisted atrioventricular connections" is a generic term for the abnormalities previously called "criss-cross heart" and "superoinferior ventricles". Both these entities show unexpected spatial relationships of the cardiac chambers and great arteries for the given segmental connections. ${ }^{1-5}$ The pathognomonic features of these hearts are the loss of the normal parallel atrioventricular connection axes; the angulated or curved configuration of the atrial and ventricular septums; the unusual relationship of the atriums, ventricles and great arteries; and the presence of abnormal recesses in the atriums and ventricles. These morphological features can be easily understood if it is assumed that, subsequent to septation, the heart has twisted along its long axis from base to apex.
With the exception of one illustrated example of double inlet left ventricle ${ }^{10}$, twisted atrioventricular connections have been found exclusively in hearts with biventricular atrioventricular connections. ${ }^{1-10}$ The solitary case with double inlet, nonetheless, shows that it is possible for the atriums to be connected to the same ventricle in such a fashion that there is crossing of the axes of the two atrioventricular valves. ${ }^{10}$ This is no more than to be expected, since hearts with overriding or straddling atrioventricular valves, which are intermediate between hearts having biventricular connections

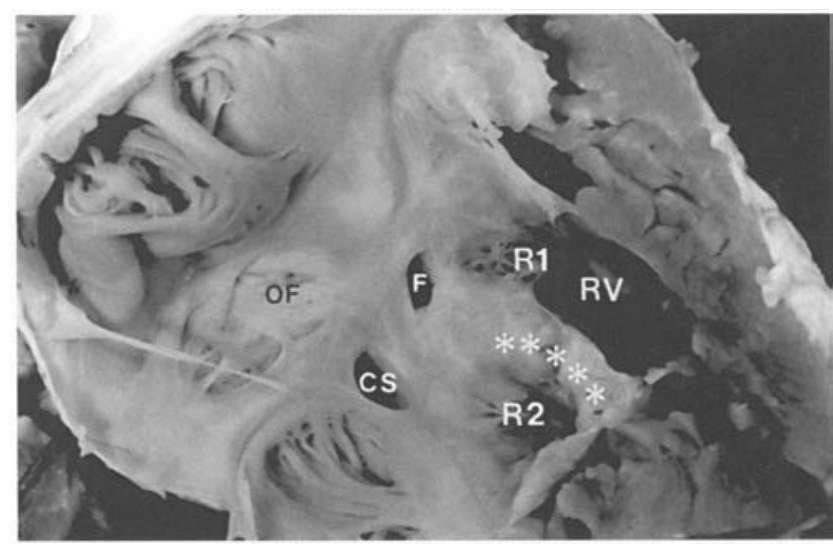

(a)

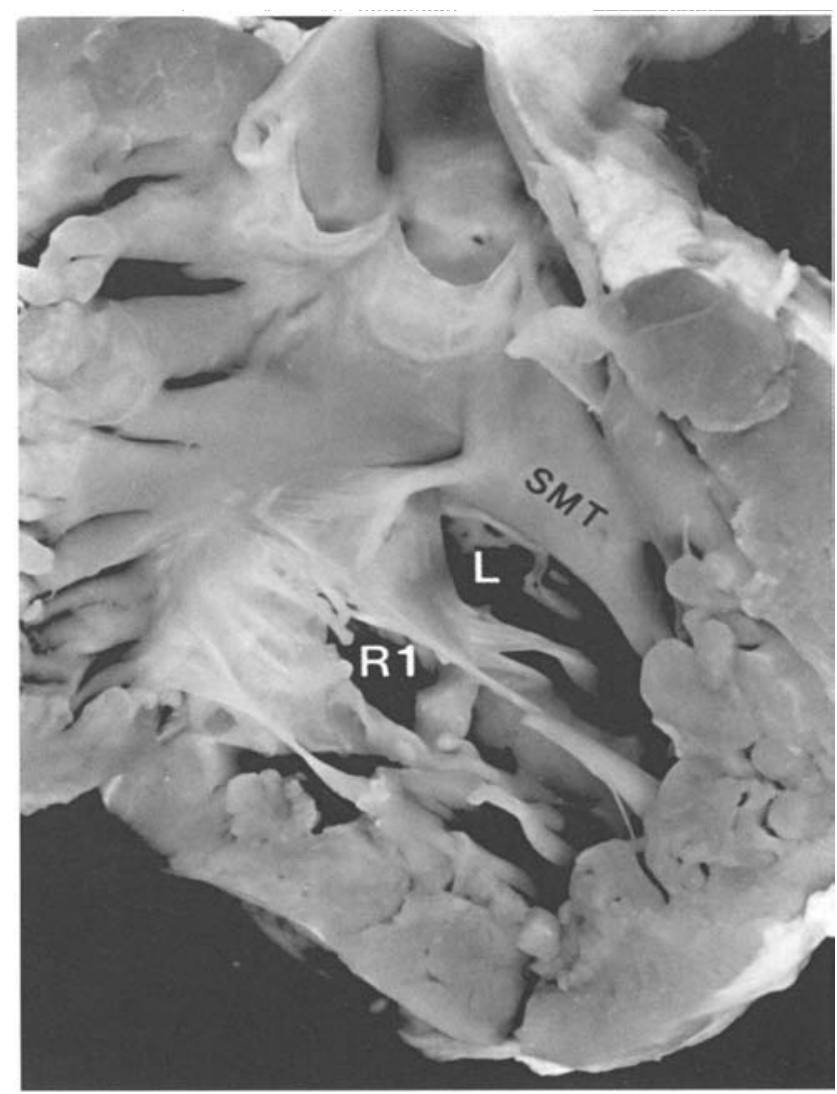

(b) 


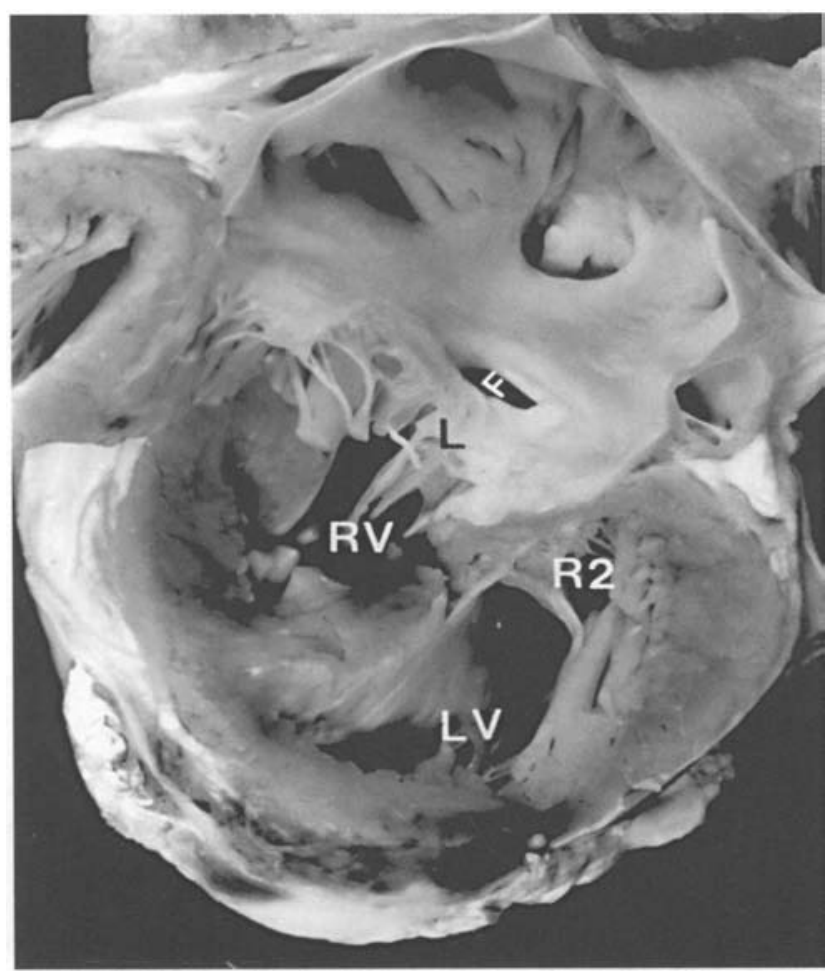

(c)

\section{Figure 4 .}

The antopsied specimen. A. The opened right atrium and right ventricle. The atrioventricular valve of the right atrium is divided into two orf fices ( $R 1$ and R2) by the bridging valvar tissue (asterisks). The superior orifice ( $R 1)$ connects the right atrium to the right ventricle $(R V)$. The inferior orifice $(R 2)$ directs the right atrial flow to the left ventricle, which is not sbonu in this photograph. Notice a fenestration $(F)$ in the basal part of the atroventricular valve leaflet that is fused with the opposing leaflet of the atroventricular valve of the left atrium. $B$. The opened right ventricle shows the superior orifice of the atrioventricular valve of the right atrum. The atrioventricular valve of the left atrium $(L)$ is seen behind the superior component of the right atroventricular valve. C. The opened left atrum and ventricles show the superoinferior relationship of the ventricles and curved configuration of the intervening ventricular septum. The left atrium is connected to the superiorly located right ventricle by the atrioventricular valve marked as $L$. The free margin of the inferior component $(R 2)$ of the atroventricular valve of the right atrium is seen within the inferiorly located left ventricle $(L V)$. Notice the different direction of the atroventricular opening axes. The fenestration $(F)$ in the atrioventricular valvar leaflet is the left side of the fenestration shown in A. D. Magnetic resonance image through the two orifices of the overriding right atrioventricular valve. The right atrium empties into both right and left ventricles through the two orifices (arrows). The axes of opening are not parallel. The left atrioventricular valve is not imaged in this view. Compare this image with the photograph shown in A. E. Magnetic resonance image through the long axis of the atrioventricular valve (arrow) between the left atrium and the right ventricle. The inferior orifice (star) of the right atrioventricular valve is seen in its short axis. The spatial orentation is mirror-imaged to that for $C$.

$C S=$ coronary sinus opening, $O F=$ oval fossa, $S M T=$ septomarginal trabeculation.

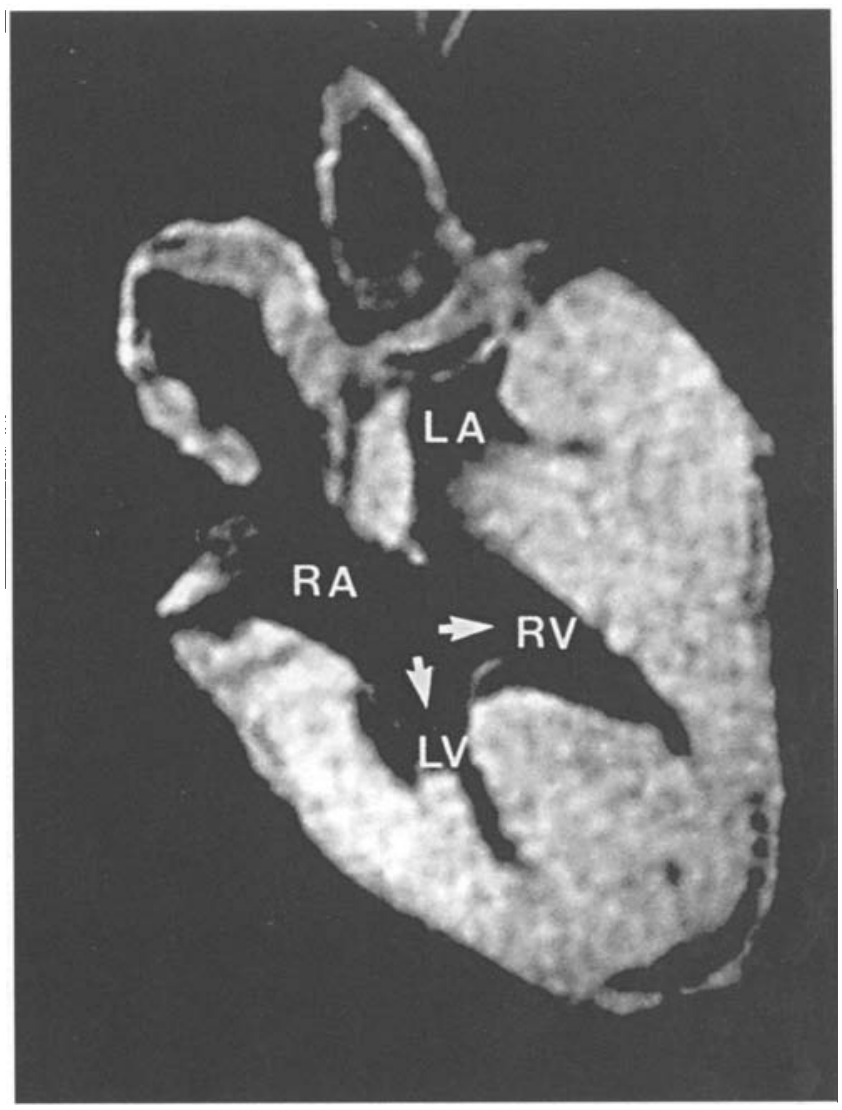

(d)

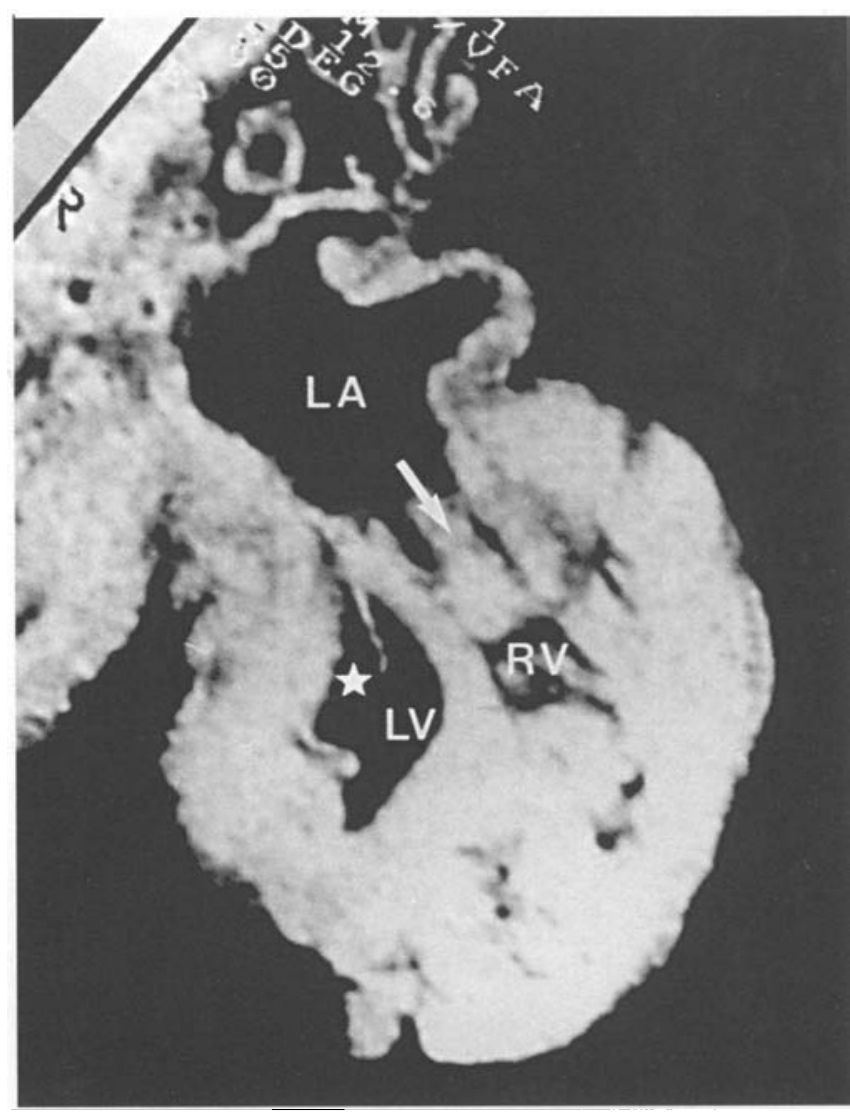

(e) 
and those with double inlet ventricle, are commonly associated with twisted atrioventricular connections. ${ }^{10-12}$ The initial illustration, however, to the best of our knowledge, has not been validated by examples seen during life. The cases described in this paper provide unequivocal evidences of twisting along the base-to-apex axis. These evidences include non-parallel axes of opening of the atrioventricular valves with a superoinferior relationship of the valves themselves, a curved configuration of the atrial septum, and an abnormal relationship of the atriums. As suggested by Anderson ${ }^{10}$, the atrioventricular valvar tension apparatuses also have an unusual arrangement within the ventricle. In this retrospective study, however, the arrangement of the papillary muscles within the ventricle was not evaluated by echocardiography.

In hearts with biventricular atrioventricular connections, twisting almost always occurs in such a way to place the right ventricular inlet, and the morphologically tricuspid valve, superior and anterior to the left ventricular inlet and the morphologically mitral valve. ${ }^{1-16}$ In other words, hearts with ventricular topology of right-hand pattern are usually twisted in a clockwise direction, while hearts with left hand ventricular topology rotate in a counterclockwise direction. In all of our cases, the atrioventricular valve connecting the right atrium to the right ventricle was located above the one connecting the left atrium to the right ventricle, which suggests twisting in a clockwise direction. In all cases, the rudimentary left ventricle was located at the posterior and right inferior aspect of the right ventricle. This spatial relationship is considered to be the product of clockwise twisting of a ventricular mass which exhibits right-hand topological pattern.

Our autopsied specimen is particularly interesting. It shows double inlet right ventricle, but in concert with double outlet right atrium, the latter existing because of the duplicated orifices of the straddling right atrioventricular valve. As the major orifice of the overriding and straddling right atrioventricular valve, and the entirety of the left atrioventricular valve, were within the dominant right ventricle, the atrioventricular connection was unequivocally double inlet right ventricle. As with the three living patients, the atrioventricular valve between the right atrium and right ventricle was located superior to that joining the left atrium and the right ventricle, and the axes of opening of these two atrioventricular valves were malaligned within the right ventricle.

Regardless of the modality used for imaging, twisted atrioventricular connections should be suspected when the axes of the two atrioventricular valves are malaligned. ${ }^{1,3,5,6,8,10-19}$ In extreme cases, the axes of opening of the two valves can be almost perpendicular to each other. In any given plane, therefore, one valve is imaged along its long axis, while the other valve is imaged across its short axis. As magnetic resonance imaging produces a stack of parallel images, it permits easy detection and accurate estimation of the abnormal spatial relationship of the atrioventricular valves. ${ }^{3,18,19}$ This is in contrast to echocardiography, in which truly parallel imaging is not possible, because the heart is visualized only by sweeping the transducer through the sonic windows. This caveat, however, is likely to be overcome by advances in three-dimensional imaging. In summary, we have shown unequivocally that twisted atrioventricular connections may occur in hearts with double inlet ventricle. Magnetic resonance imaging is excellent for demonstrating the clues to the diagnosis.

\section{References}

1. Yoo S-J, Choi Y-H. Twisted atrioventricular connections. In: Angrocardiograms in Congenital Heart Disease. Oxford University Press, New York, 1991, pp 295-298.

2. Seo J-W, Yoo S-J, Ho SY, Lee HJ, Anderson RH Further morphological observations on hearts with twisted atroventricular connections ("criss-cross hearts"). J Cardıvasc Pathol 1991;1: 211-217.

3. Yoo S-J, Seo J-W, Lim T-W, Park I-S, Hong CY, Song MG, Kim $\mathrm{SH}$, Choe KO, Cho B-K, Lee HJ. Hearts with twisted atrioventricular connections: Findings at MR imaging. Radılogy 1993;188: 109-113.

4. Edwards WD. Classification and terminology of cardiovascular anomalies. In: Emmanoutides GC, Allen HD Riemenschnerder TA, Gurgesell HP (ed). Moss and Adams Heart Disease in Infants, Children, and Adolescents Including the Fetus and Young Adult. Williams \& Wilkins, Baltımore, 1995, pp 107-131.

5 Freedom RM, Mawson JB, Yoo S-J, Benson LN. Twisted atrioventricular connections. So-called superoinferior ventricles or criss-cross heart. In: Congenital Heart Disease: Textbook of Angiocardiography. Futura Publishing Co., Armonk, 1997, pp $1313-1333$.

6. Anderson RH, Shinebourne EA, Gerlis L. Criss-cross atroventricular relationships producing paradoxical atroventricular concordance of discordance: Their significance to nomenclature of congenital heart disease. Circulation 1974;50: 176-180.

7. Van Praagh R, Weınberg PM, Van Praagh S. Malposition of the heart. In: Moss AJ, Adams FH, Emmanoulides GC (ed). Heart Disease in Infants, Chıldren and Adolescents. Williams \& Wilkins, Baltimore, 1980, pp 394-417.

8. Freedom RM, Culham G, Rowe RD. The criss-cross and superonferior ventricular heart: An angiocardiographic study. Am J Cardiol 1978;42: 620-628.

9. Van Praagh S, LaCorte M, Fellows KE, Bossina K, Busch HJ, Keck EW, Weinberg PM, Van Praagh R. Superonferior ventricles: Anatomic and angiocardiographic findings in ten postmortem cases. In: Van Praagh R, Takao A, eds. Etiology and Morphogenesis of Congenital Heart Disease. Futura Publishing Co., Mount Kisco, 1980, pp 317-378.

10. Anderson RH. Criss-cross hearts revisited. Pediatr Cardiol 1982;3: 305-313. 
11. Geva T, Van Praagh S, Sanders SP, Mayer JE, Van Praagh $\mathbf{R}$ Straddling mitral valve with hypoplastic right ventricle, crisscross atrioventricular relations, double outlet right ventricle and dextrocardia Morphologic, diagnostic and surgical considerations. J Am Coll Cardiol 1991;17: 1603-1612.

12. Marino B, Sanders SP, Pasquinı L, Giannico S, Parness IA, Colan SD. Two-dimensional echocardiographic anatomy in crisscross heart. Am J Cardiol 1986;58: 325-333.

13. Anderson RH, Smith A, Wilkinson JL. Disharmony between atroventriuclar connections and segmental combinations: unusual varıants of "crisscross" hearts. J Am Coll Cardiol 1987,10: 1274-1277.

14. Seo JW, Choe GY, Chi JG. An unusual ventricular loop associated with right juxtaposition of the atrial appendages. Int $\mathrm{J}$ Cardiol 1989;25: 219-228.
15. Anderson $\mathrm{RH}, \mathrm{Ho} \mathrm{SH}$. Segmental interconnexions versus topological congruency in complex congenital malformations. Int J Cardiol 1989;25.229-233.

16. Geva T, Sanders SP, Ayres NA, O'Laughlin MP, Parness IA. Two-dimensional echocardiographic anatomy of atrioventricular alignment discordance with situs concordance. Am Heart J 1993;125: 459-464.

17. Robinson PJ, Kumpeng V, Macartney FJ. Cross sectional echocardiographic and angıocardiographic correlation in crisscross hearts. Br Heart J 1985;54: 61-67.

18. Link KM, Weesner KM, Formanek AG. MR imaging of the criss-cross heart. Am J Roentgenol 1989;152: 809-812.

19. Igarashi $H$, Kuramatsu T, Shiraishi $H$, Yanagısawa M. Criss-cross heart evaluated by color Doppler echocardiography and magnetic resonance imaging. Eur J Pediatr 1990;149: 523-525. 